Article

\title{
Hydrothermally Assisted Synthesis of Porous Polyaniline@Carbon Nanotubes-Manganese Dioxide Ternary Composite for Potential Application in Supercapattery
}

\author{
Javed Iqbal ${ }^{1}$, Mohammad Omaish Ansari 1,*(D), Arshid Numan 2 1 , S. Wageh 3,4,*, \\ Ahmed Al-Ghamdi ${ }^{3}$, Mohd Gulfam Alam ${ }^{5}$ (D), Pramod Kumar ${ }^{6}$, Rashida Jafer ${ }^{3}$, \\ Shahid Bashir ${ }^{7}$ (D) and A. H. Rajpar ${ }^{8}$ \\ 1 Center of Nanotechnology, King Abdulaziz University, Jeddah 21589, Saudi Arabia; iqbaljavedch@gmail.com \\ 2 State Key Laboratory of ASIC and System, SIST, Fudan University, Shanghai 200433, China; \\ numan.arshed@gmail.com \\ 3 Department of Physics, Faculty of Science, King Abdulaziz University, Jeddah 21589, Saudi Arabia; \\ AGAMDI@kau.edu.sa (A.A.-G.); rashida.jafer@gmail.com (R.J.) \\ 4 Physics and Engineering Mathematics Department, Faculty of Electronic Engineering, Menoufia University, \\ Menoufia 32952, Egypt \\ 5 Department of Chemistry, Faculty of Science, Islamic University of Madinah, Madinah 42351, Saudi Arabia; \\ gulfam.alam@gmail.com \\ 6 Department of Chemistry, Prof. Rajendra Singh (Rajju Bhaiya) Institute of Physical Sciences for Study and \\ Research, V. B. S. Purvanchal University, Jaunpur 222003, India; pkchemistry.2009@gmail.com \\ 7 Center for Ionics University of Malaya, Department of Physics, Faculty of Science, University of Malaya, \\ Kuala Lumpur 50603, Malaysia; shahidbashirbaig@gmail.com \\ 8 Mechanical Engineering Department, Jouf University, Sakaka 42421, Saudi Arabia; altafrajpar@yahoo.com \\ * Correspondence: omaishchem@gmail.com (M.O.A.); wswelm@kau.edu.sa (S.W.); \\ Tel.: +966-540461642 (M.O.A.)
}

Received: 23 November 2020; Accepted: 3 December 2020; Published: 5 December 2020

check for updates

\begin{abstract}
In this study, ternary composites of polyaniline (PANI) with manganese dioxide $\left(\mathrm{MnO}_{2}\right)$ nanorods and carbon nanotubes (CNTs) were prepared by employing a hydrothermal methodology and in-situ oxidative polymerization of aniline. The morphological analysis by scanning electron microscopy showed that the $\mathrm{MnO}_{2}$ possessed nanorod like structures in its pristine form, while in the ternary PANI@CNT/ $\mathrm{MnO}_{2}$ composite, coating of PANI over $\mathrm{CNT} / \mathrm{MnO}_{2}$, rods/tubes were evidently seen. The structural analysis by $\mathrm{X}$-ray diffraction and X-ray photoelectron spectroscopy showed peaks corresponding to $\mathrm{MnO}_{2}$, PANI and CNT, which suggested efficacy of the synthesis methodology. The electrochemical performance in contrast to individual components revealed the enhanced performance of PANI@CNT/ $\mathrm{MnO}_{2}$ composite due to the synergistic/additional effect of PANI, $\mathrm{CNT}$ and $\mathrm{MnO}_{2}$ compared to pure $\mathrm{MnO}_{2}$, PANI and PANI@CNT. The PANI@CNT/MnO 2 ternary composite exhibited an excellent specific capacity of $143.26 \mathrm{C} \mathrm{g}^{-1}$ at a scan rate of $3 \mathrm{mV} \mathrm{s}^{-1}$. The cyclic stability of the supercapattery (PANI@CNT/ $\mathrm{MnO}_{2} /$ activated carbon)—consisting of a battery type electrode-demonstrated a gradual increase in specific capacity with continuous charge-discharge over 1000 cycles and showed a cyclic stability of $119 \%$ compared to its initial value after 3500 cycles.
\end{abstract}

Keywords: conducting polymer; polyaniline; $\mathrm{MnO}_{2} ; \mathrm{CNT}$; supercapattery; energy storage device

\section{Introduction}

Due to the continuous depletion of fossil fuels and the general awareness toward environmental protection and sustainable living, there is an ongoing search for an alternative renewable energy 
source [1]. The problem with the renewable sources are their unavailability sometimes, i.e., the solar sources will only produce significant energy when the intensity of the sunlight is high, and the wind will only produce energy when it is blowing [2]. Thus, to utilize newer energy sources and renewable sources, batteries and supercapacitors have attracted much interest for future energy storage devices [3]. Supercapacitors have gained tremendous attention due to their peculiar properties, such as higher magnitude of power density, charge-discharge with long cyclic stability, and higher power density than conventional batteries [4-6]. The electrode materials in supercapacitors largely determine their performance, and the ideal electrode should possess larger specific surface area (to ensure high specific capacity because charge is stored on the surface of the electrodes), good conductivity to ensure high power density, long cyclic life and environmentally sustainability [7]. Generally, the supercapacitors are of two types, i.e., electrical double layer capacitors (EDLCs) and pseudo-capacitors [8,9]. In the electrical double layer capacitor, the capacitance arises from the electrode/electrolyte interface charge separation, while in the pseudo capacitor it is because of the fast reversible faradaic reactions that occur at the surface of the electrodes [10].

Carbon materials show EDLC and have fast charge-discharge characteristics with long cyclic stability, but in contrast they possess relatively low capacitance $\left(100 \sim 300 \mathrm{~F} \mathrm{~g}^{-1}\right)$ and energy density $\left(<10 \mathrm{Wh} \mathrm{kg}^{-1}\right)$ [11]. In recent years, the use of carbon nanotubes (CNTs) as EDCLs has gained attention because of properties of elevated conductivity, high surface area, long stability, mechanical strength, and knittability [12]. However, due to their low specific capacity and energy density they cannot beat the pseudocapacitors due to their inherited electrostatic surface charging mechanism. Thus, the best way to utilize CNTs is to combine them with conducting polymers and metal oxides.

Out of various conducting polymers, polyaniline (PANI) stands far apart due to its low cost, simple synthesis protocol, controllable redox states, controllable morphology and tunable conductivity [13]. Deng et al. [14] interpreted that the higher capacitance of $183 \mathrm{~F} \mathrm{~g}^{-1}$ of PANI@CNT in contrast to capacitance of $47 \mathrm{~F} \mathrm{~g}^{-1}$ for CNT is due to the pseudocapacitance provided by the uniformly coated PANI over CNT. Similarly, Sharma et al. [15] in their PANI@CNT composite showed that the specific capacitance increased manifold from $49.58 \mathrm{~F} \mathrm{~g}^{-1}$ for CNT to $597.82 \mathrm{~F} \mathrm{~g}^{-1}$ in PANI@CNT at scan rate of $2 \mathrm{mV} \mathrm{s}^{-1}$. As for metal oxides, $\mathrm{MnO}_{2}$ is a suitable candidate owing to its pseudocapacitive properties, wide availability, low toxicity and ease of preparation [16]. $\mathrm{MnO}_{2}$ possess high theoretical capacity of $1370 \mathrm{~F} \mathrm{~g}^{-1}$ suggesting a single-electron redox reaction of all manganese atoms, broad potential window and good electrochemical characteristics in neutral electrolyte [17]. Despite these, the specific capacitance of $\mathrm{MnO}_{2}$ is far less than the expected value. This might be due to its poor electronic conductivity of $10^{-5}-10^{-6} \mathrm{~S} \mathrm{~cm}^{-1}$, low ionic diffusion constant of $\sim 10^{-13} \mathrm{~cm}^{2} \mathrm{~V}^{-1} \mathrm{~s}^{-1}$, low structural stability and high particle aggregation at nanoscale [18]. The incorporation of $\mathrm{MnO}_{2}$ into porous materials is one of the ways to enhance its performance for effective utilization as electrode materials. Li et al. [19] showed that $\mathrm{MnO}_{2} @ \mathrm{CNT}$ nanocomposite possessed high specific capacitance of $201 \mathrm{~F} \mathrm{~g}^{-1}$ with cyclic stability of over 10,000 cycles. They interpreted that the bonding of $\mathrm{MnO}_{2}$ and CNTs reduces the contact resistance leading to simplification of Faraday reaction for the electrochemically active species. The synergized effect of conductive CNTs and pseudocapacitive $\mathrm{MnO}_{2}$ leads to enhanced capacitance. Similarly, Liu et al. [20] showed high pseudocapacitive nature in PANI@MnO nanocomposite electrodes. Apart from the pseudocapacitive behavior, they interpreted that the high capacitance is due to the special nanostructure and high porosity which provides effective diffusion channels for the electrolyte ions. On the basis of the above based discussion, it can be interpreted that nanostructured porous composites of PANI, CNT and $\mathrm{MnO}_{2}$ can be exciting materials for the fabrication of supercapattery with enhanced performance, owing to the synergistic and addition effect of pseudocapacitance and electrical double layer capacitance.

Thus, in this work ternary composite of PANI, CNT and $\mathrm{MnO}_{2}\left(\mathrm{PANI} @ \mathrm{CNT} / \mathrm{MnO}_{2}\right)$ was prepared by the combination of hydrothermal methodology and in-situ oxidative polymerization. The $\mathrm{MnO}_{2}$ in the reaction mixture acted as oxidant and its dissolution and penetration into PANI network resulted in the generation of porosity in the PANI chains. The porosity and penetration of $\mathrm{MnO}_{2}$ inside leads 
to good contact between the constituents, i.e., PANI, CNT and $\mathrm{MnO}_{2}$. The high specific capacity of $131.27 \mathrm{C} \mathrm{g}^{-1}$ along with stability of over $119 \%$ cycles holds promise for its application in future enhanced supercapattery devices.

\section{Materials and Methods}

\subsection{Materials}

Aniline and activated carbon (AC) was purchased from Sigma Aldrich. Potassium per manganate (PPs), potassium per sulphate, N-methyl-2-pyrrolidone (NMP), $\mathrm{HCl}(35 \%)$ and ethanol was purchased from Otto chemicals. The CNTs with a diameter of 10-20 nm and length $\sim 20 \mu \mathrm{m}$ were purchased from Hanwha Nanotech, South Korea. The water used in the experiments was deionized water.

\subsection{Synthesis of $\mathrm{MnO}_{2}$, PANI, PANI@CNT and PANI@CNT/MnO}

$\mathrm{MnO}_{2}$ nanorods were prepared by hydrothermal methodology. In this protocol, $0.658 \mathrm{~g}$ of $\mathrm{KMnO}_{4}$ was dissolved in $75 \mathrm{~mL}$ of water and to which $1.5 \mathrm{~mL}$ of $\mathrm{HCl}$ was added. The whole system was put under continuous stirring for $15 \mathrm{~min}$ and thereafter the solution was charged into Teflon lined hydrothermal reactor of volume $100 \mathrm{~mL}$ and kept at $140{ }^{\circ} \mathrm{C}$ for $24 \mathrm{~h} \mathrm{[21].} \mathrm{The} \mathrm{final} \mathrm{brown} \mathrm{color}$ indicated successful formation of $\mathrm{MnO}_{2}$. Afterwards centrifugation was used to separate prepared $\mathrm{MnO}_{2}$, which was then washed with excess of water and ethanol and subsequently dried at $100{ }^{\circ} \mathrm{C}$ for $6 \mathrm{~h}$. PANI@CNT was prepared by in-situ oxidative polymerization of aniline in the presence of CNT. To $100 \mathrm{~mL}$ of $0.1 \mathrm{M} \mathrm{HCl}$ solution, the CNTs ( $5 \mathrm{wt} \%$ of aniline) were dispersed by stirring and ultrasonic bath. After uniform distribution of CNTs, $1 \mathrm{~g}$ of aniline was added to this dispersion for proper adsorption of aniline monomer on CNTs and subsequently the solution of oxidant (1.45 g PPs in $100 \mathrm{~mL}$ $1 \mathrm{M} \mathrm{HCl}$ ) was added to start the polymerization. The reaction mixture turned into greenish black which was filtered after $24 \mathrm{~h}$, washed with water and ethanol and eventually dried at $100{ }^{\circ} \mathrm{C}$ for $6 \mathrm{~h}$ to get PANI@CNT. Pure PANI was also prepared similarly but without CNTs. For PANI@CNT/MnO ${ }_{2}$, similar methodology as of PANI@CNT was adopted but for the addition of oxidant step. Here a slight modification was done and to the dispersion of aniline and CNTs in $100 \mathrm{~mL}$ of $1 \mathrm{M} \mathrm{HCl}$ solution, a $100 \mathrm{~mL}$ dispersion of $0.2 \mathrm{~g}$ of $\mathrm{MnO}_{2}$ in $1 \mathrm{M} \mathrm{HCl}$ was added to affect the polymerization.

\subsection{Characterization}

The morphological and compositional analysis of $\mathrm{MnO}_{2}$, PANI, PANI@CNT and PANI@CNT/ $\mathrm{MnO}_{2}$ was conducted by Field emission scanning electron microscopy (FESEM, JSM-7600F (JEOL, Tokyo, Japan)) and energy dispersive X-ray spectroscopy (EDS, Oxford Instruments, High Wycombe, UK). For the crystal structure and phase determination analysis, X-ray diffraction (XRD) was performed in $2 \theta$ range of $10^{\circ}-90^{\circ}$ (Rigaku, Ultima IV, Tokyo, Japan). Raman analysis was done by Thermo Fisher Scientific instrument (DXR Raman Microscope, Madison, WI, USA). For the elemental analysis and interactions between the constituents, X-ray photoelectron spectroscopy (XPS) (PHI 5000 Versa Probe II, Physical Electronics, Chanhassen, MN, USA) was performed at $\sim 10^{-10} \mathrm{~m}$ bar.

\subsection{Electrodes Development and Electrochemical Analysis}

To develop supercapattery, the prepared composites were used as the positive and AC as the negative electrode. For the fabrication of electrodes, active materials $\left(\mathrm{MnO}_{2}, \mathrm{PANI}\right.$, PANI@CNT and PANI@CNT/ $\mathrm{MnO}_{2}$ ) were coated by drop cast method on nickel foam of $1 \times 1 \mathrm{~cm}^{2}$ area. Firstly, a slurry was prepared by mixing the active material $(75 \%), \mathrm{AC}(15 \mathrm{wt} \%)$, and PVdF $(10 \mathrm{wt} \%)$ in NMP and was stirred at ambient conditions for $24 \mathrm{~h}$ in order to get a homogenous slurry. The slurry was coated on the nickel foam by drop casting and was subsequently heated at $90^{\circ} \mathrm{C}$ for $12 \mathrm{~h}$. The active material was loaded on all electrodes in the mass of $\sim 5.00 \mathrm{mg}$.

An electrochemical workstation (Gamry Interface 1000 Instrument, Warminster, PA, USA) was utilized to examine the electrochemical behavior. A potential window of $0-0.5 \mathrm{~V}$ was used in cyclic 
voltammetry $(\mathrm{CV})$ versus $\mathrm{Ag} / \mathrm{AgCl}$ reference electrode. The current densities of 0.3 to $0.8 \mathrm{~A} \mathrm{~g}^{-1}$ at $0.5 \mathrm{~V}$ were used for galvanostatic-charge-discharge (GCD) studies and electrochemical impedance spectroscopy (EIS) was carried out in the range $0.01-100 \mathrm{kHz}$ at a fixed AC voltage of $10 \mathrm{mV}$ (RMS, root mean square potential amplitude). All electrochemical measurements were performed in $0.1 \mathrm{M}$ $\mathrm{KOH}$ aqueous electrolyte.

\section{Results and Discussion}

\subsection{Morphological Characterizations}

The SEM micrographs of $\mathrm{MnO}_{2}$, PANI, PANI@CNT and PANI@CNT/MnO $\mathrm{M}_{2}$ are presented in Figure 1. In the case of $\mathrm{MnO}_{2}$, highly monodispersed $\mathrm{MnO}_{2}$ rods with shaped defined edges can be clearly seen (Figure 1a). The diameter of the rods varies from $60-120 \mathrm{~nm}$ while its length is in the range of 500-600 nm with many intermediate smaller sized rods also in the vicinity. It can be interpreted that the presence of many smaller particles on $\mathrm{MnO}_{2}$ or smaller sized rods may be due to the breakage of larger rods or due to the small amount of $\mathrm{KMnO}_{4}$ which failed to grow into rods [22]. Pure PANI showed fibrous morphology of diameter $\sim 30-70 \mathrm{~nm}$ with some larger fibers of length exceeding $400 \mathrm{~nm}$ while some smaller sized rods are also seen (Figure 1b). The fibrous morphology of PANI is due to the fast polymerization of aniline during the rapid mixing technique as explained in our previous report [23]. In the case of PANI@CNT, similar morphology as in the case of PANI was observed with little or no observance of CNT owing to the surface coating of PANI over it (Figure 1c) [24]. The ternary composite PANI@CNT/MnO $\mathrm{Mn}_{2}$ showed striking different morphology of PANI coated CNT/MnO 2 , with fibers showing interrupted or rough surface which is completely different to that of pure PANI and $\mathrm{MnO}_{2}$ (Figure 1d). It can be interpreted that the part of $\mathrm{MnO}_{2}$ which oxidizes aniline to PANI, dissolves or disintegrates during the genesis of PANI tubes leading to the breakage and rough outer surface of PANI. The rough interwoven fibrous and porous structure of PANI@CNT/MnO $\mathrm{M}_{2}$ is expected to provide enhanced surface area and will provide channels for the transport of ions or charge carriers.

The EDS analysis of PANI@CNT/MnO 2 in Figure 2 shows the presence of $C$ which corresponds to the carbon skeleton of PANI and CNT, the N corresponds to the imine group of PANI, while the presence of $\mathrm{Mn}$ and $\mathrm{O}$ confirms the presence of $\mathrm{MnO}_{2}$. The small amount of $\mathrm{Cl}$ confirms the acid doping of PANI@CNT/MnO 2 composite.

The elemental mapping of PANI@CNT/ $\mathrm{MnO}_{2}$ also showed the presence of $\mathrm{C}, \mathrm{N}, \mathrm{O}, \mathrm{Mn}$ and $\mathrm{Cl}$ with homogenous dispersion which suggests the efficacy of the synthesis methodology (Figure 2).

\subsection{X-ray Diffraction and Raman Studies}

The XRD analysis of $\mathrm{MnO}_{2}$, PANI, PANI@CNT and PANI@CNT/ $\mathrm{MnO}_{2}$ is presented in Figure 3a. In the case of $\mathrm{MnO}_{2}$, the prominent peaks at $2 \theta=12.71^{\circ}, 17.99^{\circ}, 28.69^{\circ}, 37.54^{\circ}, 42.03^{\circ}, 49.80^{\circ}, 56.30^{\circ}$ and $60.30^{\circ}$ corresponds well to the crystal planes of $\alpha-\mathrm{MnO}_{2}$ (JCPDS card PDF file no. 44-0141) [25]. PANI emeraldine salt showed a prominent peak at $2 \theta=25.28^{\circ}$ with a slight shoulder at $2 \theta=\sim 15$ and 20 corresponding to the 322, 121 and 113 planes respectively, suggesting that most of the PANI is ordered along these crystal planes [26]. The maximum sharpness of 322 plane peak suggests that most of the arrangement is periodicity perpendicular to the polymer chain [27]. PANI@CNT shows two peaks at $2 \theta=\sim 25.60^{\circ}$ and $43^{\circ}$ corresponding to the reflections due to the graphitic $\left(\begin{array}{lll}0 & 0 & 2\end{array}\right)$ and $\left(\begin{array}{lll}1 & 0 & 0\end{array}\right)$ planes [28]. The peak at $2 \theta=\sim 25^{\circ}$ of CNT also coincided with the 322 peak of PANI, but in contrast to pure PANI, the XRD peak of PANI@CNT at $2 \theta=\sim 25^{\circ}$ is much shaper and intense owing to the high crystallinity of CNTs. The ternary composite PANI@CNT/MnO ${ }_{2}$ shows all the reflections of PANI, $\mathrm{CNT}$ and $\mathrm{MnO}_{2}$ which suggest successful intercalation of the constituents. However, the peaks are of much reduced intensity which might be due to in-situ oxidation of aniline by $\mathrm{MnO}_{2}$ as it might result in the disruption of $\mathrm{MnO}_{2}$ crystals during its dissolution, coating of $\mathrm{MnO}_{2}$, PANI or by both over CNT. 


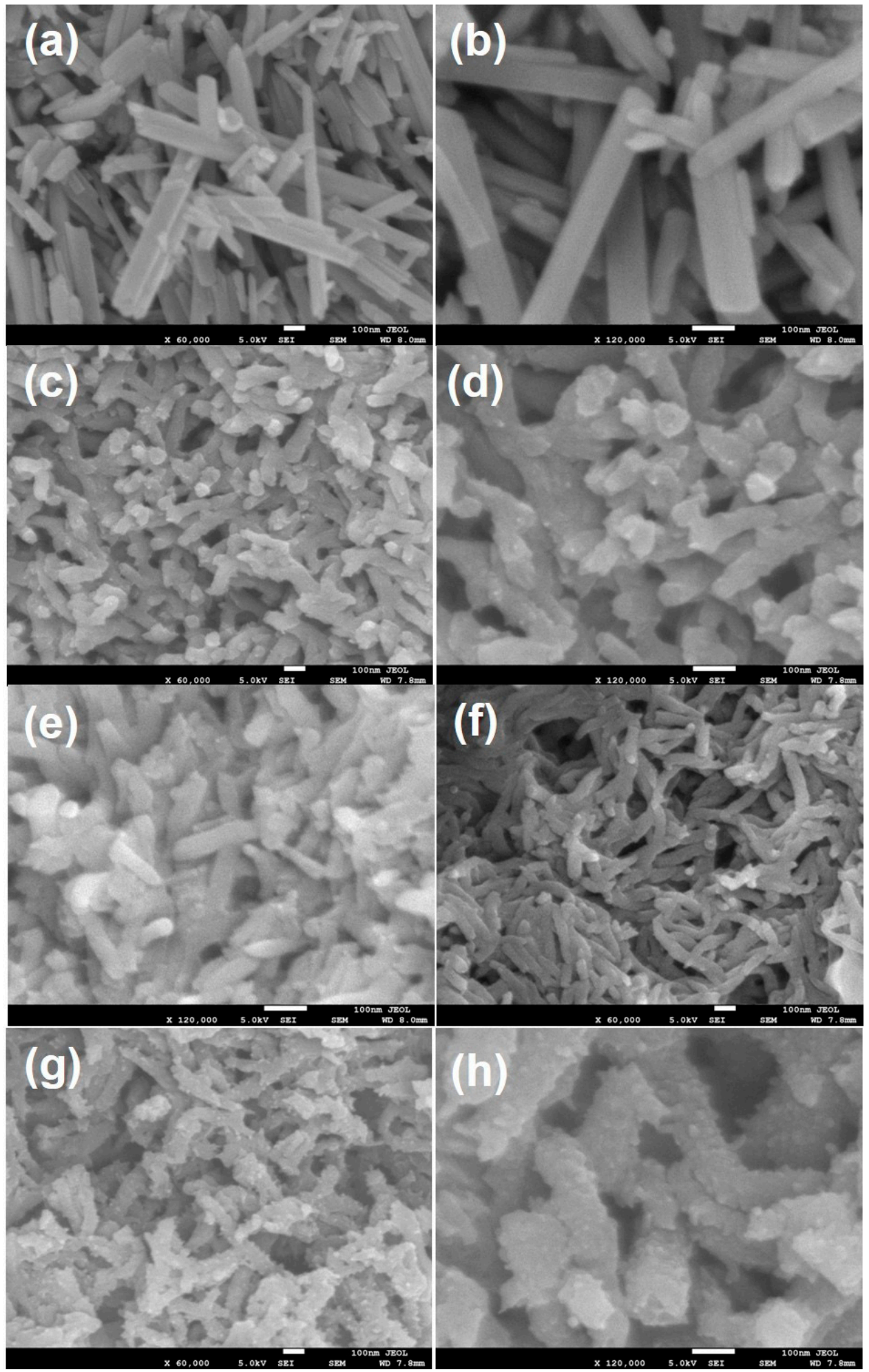

Figure 1. Field emission scanning electron microscopy (FESEM) images of $(\mathbf{a}, \mathbf{b}) \mathrm{MnO}_{2}$ nanorods, $(\mathbf{c}, \mathbf{d})$ polyaniline (PANI), (e,f) PANI@CNT and (g,h) PANI@CNT/MnO 2 showing $\mathrm{MnO}_{2}$ and carbon nanotubes (CNTs) decorated/embedded in PANI fibrous network. 

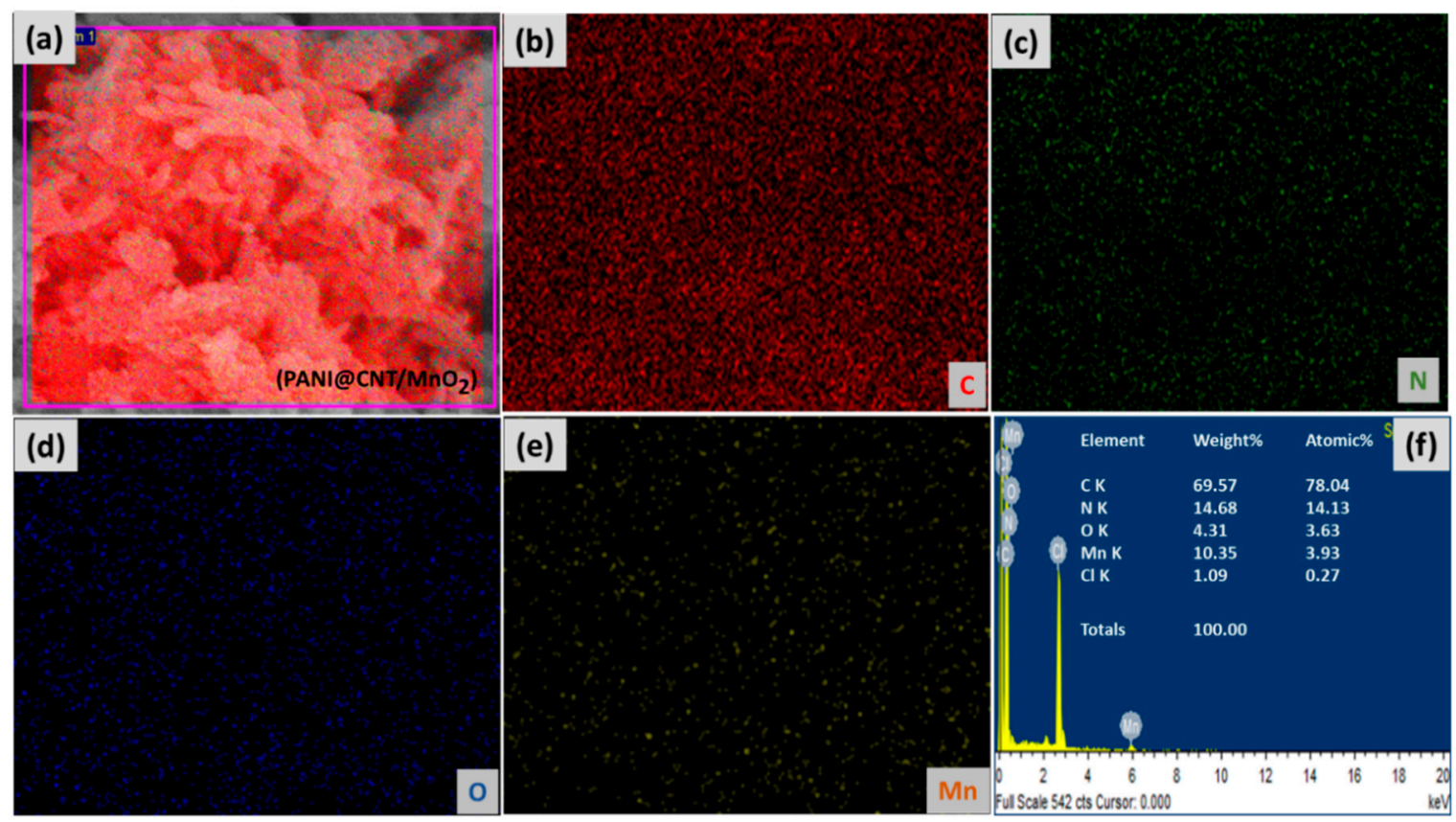

Figure 2. (a) Energy dispersive X-ray spectroscopy (EDS) elemental mapping of PANI@CNT/MnO (b) C, (c) N, (d) O, (e) Mn, and (f) compositional spectra of the PANI@CNT/MnO 2 ternary composite.
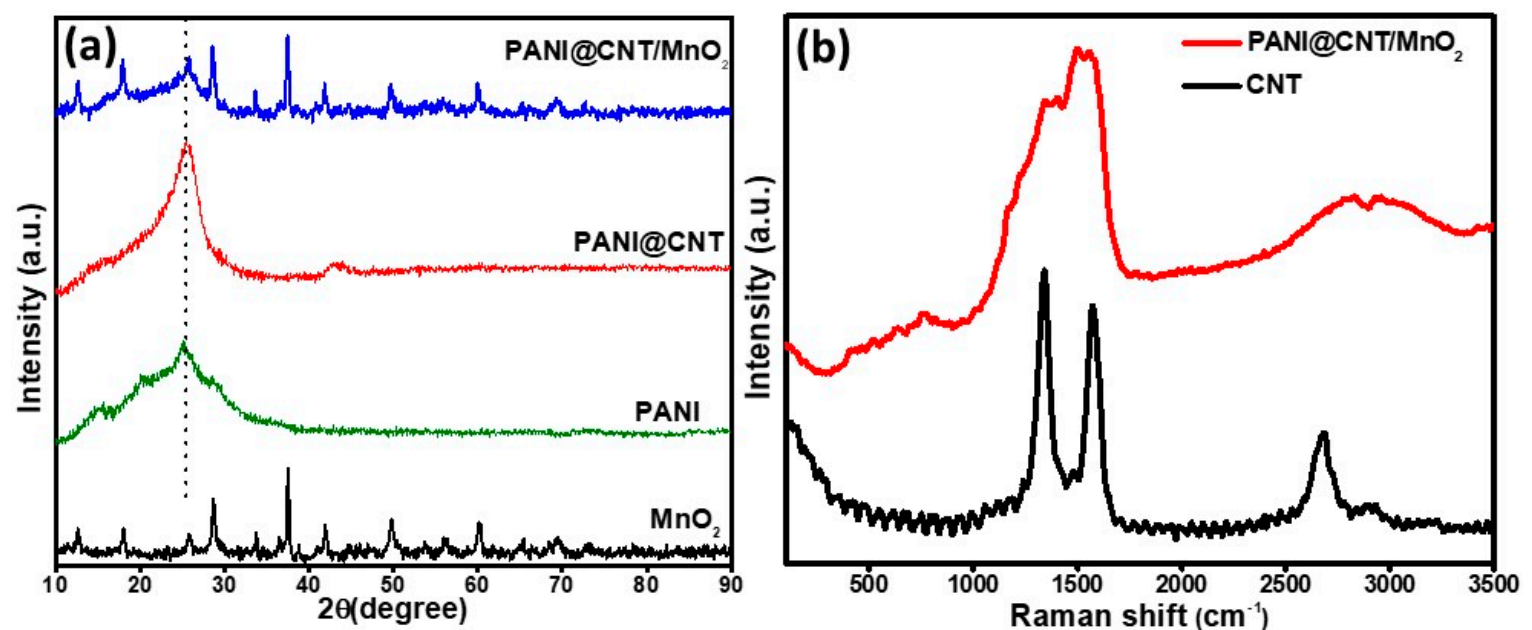

Figure 3. (a) X-ray diffraction (XRD) pattern of the $\mathrm{MnO}_{2}$, PANI, PANI@CNT binary and PANI@CNT/ $\mathrm{MnO}_{2}$ ternary composites scanned in the $2 \theta$ range of $10-90^{\circ}$ and (b) Raman spectra of the pure CNT and PANI@CNT/ $\mathrm{MnO}_{2}$ ternary composite.

The Raman spectra of CNT and PANI@CNT/MnO 2 is presented in Figure 3b. Pure CNT shows a typical $\mathrm{G}$ band (derived from the graphite like mode) at $1580 \mathrm{~cm}^{-1}$. The defects or disorder induced D-band gap is situated at $1346 \mathrm{~cm}^{-1}$ [29]. After coating with PANI and $\mathrm{MnO}_{2}$ in PANI@CNT/MnO the spectra of PANI is dominant which confirms good coating of CNT with PANI [30].

\subsection{X-ray Photoelectron Spectroscopy Studies}

The XPS analysis was done to study the composition and chemical states of PANI@CNT/MnO (Figure 4). The survey scan of PANI@CNT/MnO 2 (Figure 4a) shows the presence of five major sets of peaks corresponding to $\mathrm{C}, \mathrm{N}, \mathrm{O}, \mathrm{Cl}$ and $\mathrm{Mn}$ without the observance of any other impurities. The $\mathrm{C} 1 \mathrm{~s}$ peak corresponds to the residual carbon of the sample and carbon from the XPS instrument. The C1s peak (Figure $4 \mathrm{~b}$ ) can be deconvoluted into three peaks at 284.71, 285.85 and $288.92 \mathrm{eV}$ corresponding to 
the aliphatic carbon $\mathrm{C}-\mathrm{C} / \mathrm{C}-\mathrm{H}, \mathrm{C}-\mathrm{O}-\mathrm{C}$ and $\mathrm{O}-\mathrm{C}=\mathrm{O}$ [31]. The $\mathrm{C}-\mathrm{O}-\mathrm{C}$ and $\mathrm{O}-\mathrm{C}=\mathrm{O}$ also represents some additional functionality of PANI and $\mathrm{CNT}$ which might acts as sites for interaction with each other or $\mathrm{MnO}_{2}$.
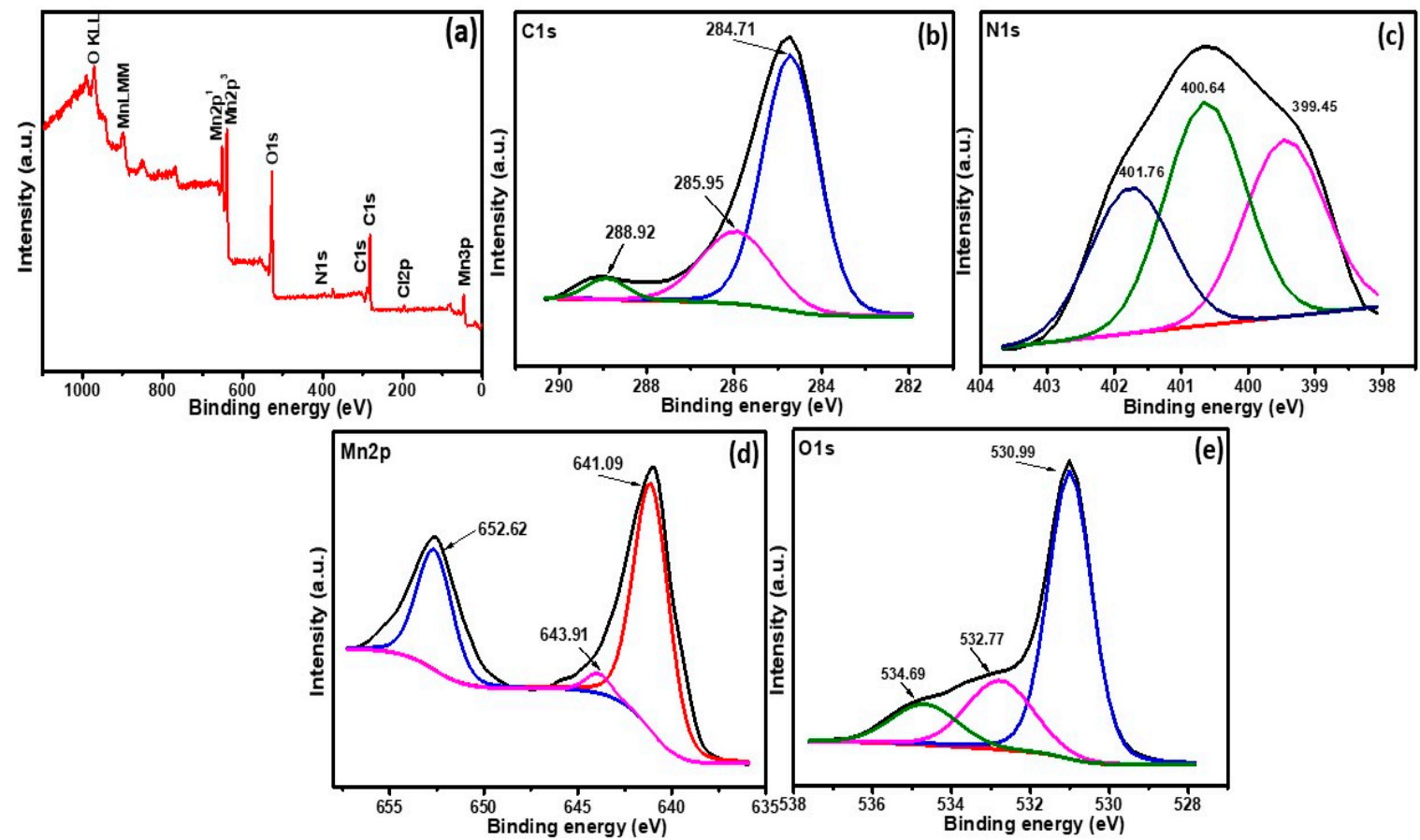

Figure 4. (a) A survey spectrum of PANI@CNT/MnO 2 ternary composite, core-level XPS spectra of (b) C 1s, (c) N 1s, (d) Mn 2p and (e) O 1s.

The N1s peak (Figure 4d) can be deconvoluted into three peaks at 399.45, 400.64 and $401.76 \mathrm{eV}$ corresponding to the pyridinic nitrogen, pyrrolic nitrogen/pyridone nitrogen in association with oxygen functionality and quaternary nitrogen respectively [32]. In Mn2p spectra (Figure 4e) two peaks at 638 and $649 \mathrm{eV}$ with a separation gap of $\sim 11 \mathrm{eV}$ can be attributed to the Mn2p3/2 and Mn2p1/2 respectively. These values are in agreement with the previous reports and indicate +4 oxidation state of $\mathrm{Mn}$ [33]. This also suggests successful synthesis of $\mathrm{MnO}_{2}$ and also its state has not changed in the ternary composite. In the O1s spectra (Figure 4e) the $530.99 \mathrm{eV}$ can be associated with the oxygen attached to Mn. The other bands at 532.77 and $534.69 \mathrm{eV}$ is due to organic $\mathrm{C}=\mathrm{O}$ or $\mathrm{H}-\mathrm{O}-\mathrm{H}$ and $\mathrm{C}=\mathrm{O}$, respectively [34]. The small amount of $\mathrm{Cl}$ in the survey scan is from $\mathrm{HCl}$ due to the acid doping of PANI.

\subsection{Three Electrodes Electrochemical Studies of $\mathrm{MnO}_{2}$, PANI, PANI@CNT and PANI@CNT/MnO $\mathrm{M}_{2}$}

Electrochemical studies of the as synthesized ternary composite and its variants were carried out in an alkaline medium ( $0.1 \mathrm{M} \mathrm{KOH})$ in the potential range of 0 to $0.5 \mathrm{~V}$ using $\mathrm{Ag} / \mathrm{AgCl}$ as reference and platinum wire as counter electrode through cyclic voltammetry $(\mathrm{CV})$, galvanostatic charge-discharge (GCD) at various current densities (0.3-0.8 $\mathrm{A} \mathrm{g}^{-1}$ ) and electrochemical impedance spectroscopy (EIS) in a standard three electrodes cell system. Figure 5 shows the electrochemical signature of $\mathrm{MnO}_{2}$, PANI, PANI@CNT and PANI@CNT/ $\mathrm{MnO}_{2}$ at different scan rates from 3 to $50 \mathrm{mV} \mathrm{s}{ }^{-1}$. The lowest and the highest scan rates demonstrate the stability and rate capability of the electrode materials [35]. In each case the redox peaks in the voltammograms can be observed, demonstrating the occurrence of faradic reaction at the electrode which is the property of a battery grade material [36]. Figure 5a shows the $\mathrm{MnO}_{2} \mathrm{CV}$ curves at different scan rates. There is a linear increase in the current densities when the scan rates were increased showing the good electrochemical behavior and reached to the maximum current density of $19.88 \mathrm{~mA} \mathrm{~g}^{-1}$ at a scan rate of $50 \mathrm{mV} \mathrm{s}^{-1}$ as a standalone electrode material 
when the particles size is in the nano regime [37]. The metal oxides in their pristine forms tend to aggregate, which reduced the electrochemical active sites of the nanomaterials and ultimately affected the electrochemical activity of the electrode materials. In the case of PANI (Figure $5 b$ ), when scanned from 3 to $50 \mathrm{mV} \mathrm{s}^{-1}$, a maximum current density of $74.76 \mathrm{~mA} \mathrm{~g}^{-1}$ was observed because PANI is well known conducting polymer and its fibrous morphology is most conductive in nature compared to nanospheres and nanorods [38]. Figure 5c represents CV curves of PANI@CNT. Carbon nanotubes have excellent conductivity and thermal stability. Therefore, due to the additional effect the current density of PANI@CNT was increased to $126.37 \mathrm{~mA} \mathrm{~g}^{-1}$ at $50 \mathrm{mV} \mathrm{s}^{-1}$ compared to pure PANI. However, the maximum current density $\left(154.84 \mathrm{~mA} \mathrm{~g}^{-1} @ 50 \mathrm{mV} \mathrm{s}^{-1}\right)$ was achieved in the case of the ternary composite, PANI@CNT/MnO 2 as demonstrated in Figure 5d, which could be due to the synergistic effect of CNT and $\mathrm{MnO}_{2}$ nanoparticles in the ternary composite [39]. Additionally, the porous nature of the ternary composite plays a pivotal role in the perforation of counter ions that help to enhance the conductivity of the active material. When the $\mathrm{MnO}_{2}$ nanorods are embedded in the polymer matrix the phenomena of de-aggregation occurred, which helped to expose the more electroactive site of the $\mathrm{MnO}_{2}$ nanoparticles. Due to the de-aggregation of $\mathrm{MnO}_{2}$ nanoparticles and addition of CNT in polymer matrix, the highest conductivity was achieved due to the synergistic effect of the contributing components in ternary composite as shown in comparison plot (Figure $5 \mathrm{~d}$ ). In all cases, there is a slight peak potential shift at high scan rates due to the asynchronous movement of the counter ions. These results are providing the evidence of useful strategy that a combination of three components (PANI, CNT, $\mathrm{MnO}_{2}$ ) in the form of composite by a facile synthesis protocol and porosity can produce enhanced electrochemical signature than the individuals. A comparison plot (Figure 5e) of all variants shows the systematic increase in the current densities. The specific capacity $\left(Q_{S}\right)$ for all electrode materials from CV curves was calculated using the following Equation (1) [40]:

$$
Q_{S}=\frac{1}{m v} \int_{V \mathrm{i}}^{V \mathrm{f}} I \times V \mathrm{~d} V
$$

where $Q_{S}, m, v$, and integral part of the equation represent specific capacity $\left(\mathrm{C} \mathrm{g}^{-1}\right)$, active mass $(\mathrm{g})$, scan rate $\left(\mathrm{mV} \mathrm{s}^{-1}\right)$ and area under the I-V curve respectively. The $Q_{S}$ values calculated at $3 \mathrm{mV} \mathrm{s}^{-1}$ for $\mathrm{MnO}_{2}$, PANI, PANI@CNT, and PANI@CNT/ $\mathrm{MnO}_{2}$ are 34.71, 86.02, 118.47, and $143.26 \mathrm{C} \mathrm{g}{ }^{-1}$, respectively. The specific capacity versus scan rates is plotted in Figure $5 \mathrm{f}$. It could be concluded that specific capacity depleted at higher scan rate, but the ternary composite is the best sustaining electrode material even at high scan rate among other samples when tested under the same conditions.

The GCD studies presented in Figure 6 were conducted at a fix potential of $0.5 \mathrm{~V} \mathrm{vs.} \mathrm{Ag} / \mathrm{AgCl}$ at different current densities. It is obvious from the GCD curves (Figure $6 a-d$ ) that there is a systematic increase in the discharge time for all four variants, but the ternary composite takes a lead among all, as shown in the comparison plot (Figure 6e). The non-triangular GCD curves vouch the non-electrostatic behavior of the electrode materials. Similarly, $Q_{S}$ values were also calculated from GCD curves for all variants using the following Equation (2) [41]:

$$
Q_{S}=\frac{I \times \Delta t}{m}
$$

where $I, \Delta t$ and $m$ represent current density, discharge time and active mass in the equation, respectively. The obtained $Q_{S}$ values at current density $0.3 \mathrm{~A} \mathrm{~g}^{-1}$ are $32.98,95.04,128.73$, and $153.82 \mathrm{C} \mathrm{g}^{-1}$ for $\mathrm{MnO}_{2}$, PANI, PANI@CNT, and PANI@CNT/MnO 2 , respectively. The specific capacity values at various current densities are plotted in Figure $6 f$. It is clear the ternary composite showed the highest specific capacity and better rate capability among all other variants. 

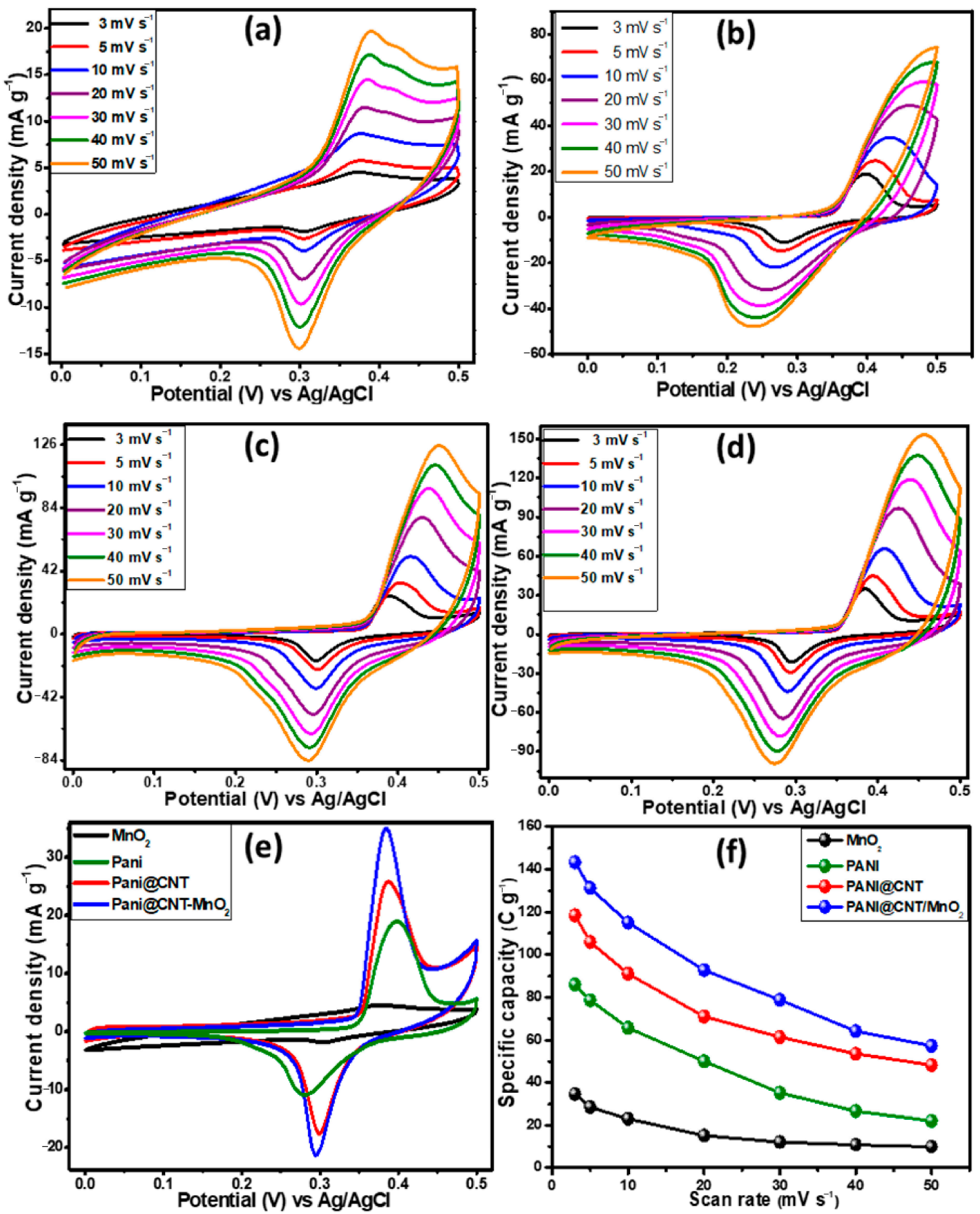

Figure 5. Cyclic voltammetry (CV) curves of (a) pristine $\mathrm{MnO}_{2}$ nanorods (b) fibrous PANI, (c) PANI@CNT binary composite, (d) PANI@CNT/MnO 2 measured at varied scan rates, (e) CV curves to compare the electrochemical performance of all variants recorded at $3 \mathrm{mV} \mathrm{s}^{-1}$, and (f) scan rate vs. specific capacity plot for all variants. 

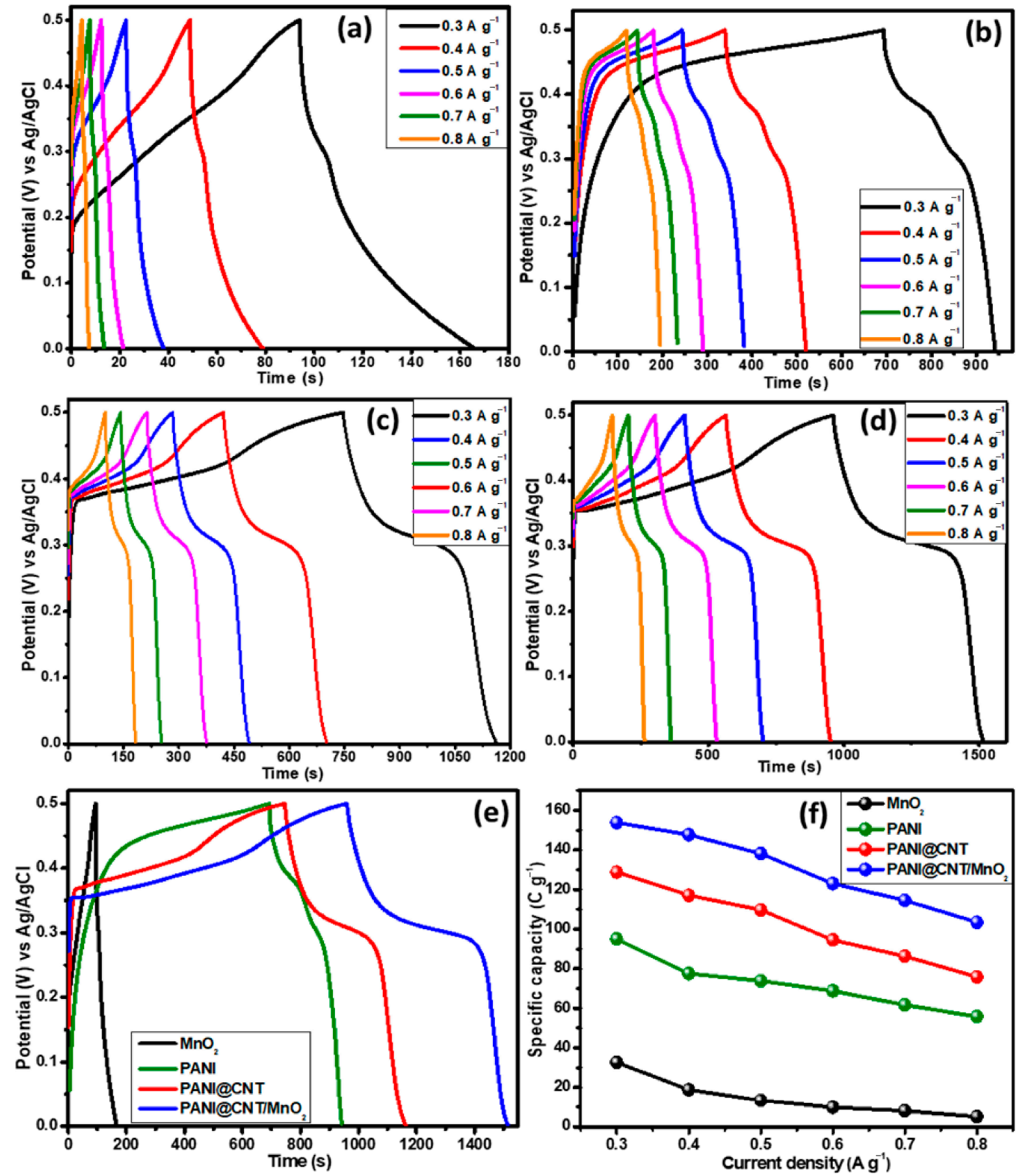

Figure 6. Galvanostatic-charge-discharge (GCD) curves at various current densities, (a) $\mathrm{MnO}_{2}$, (b) fibrous PANI, (c) PANI@CNT, (d) PANI@CNT/MnO 2 , (e) comparison curves for all four variants at a current density of $0.3 \mathrm{~A} \mathrm{~g}^{-1}$, and (f) current density vs. specific capacity plot of all four variants.

The EIS studies were conducted to analyze the intrinsic properties such as equivalent series resistance $(E S R)$, charge transfer resistance $\left(R_{c t}\right)$ and Warburg impedance. EIS studies were conducted at an alternating voltage of $10 \mathrm{mV}$ (RMS) in the frequency range of $0.01-100 \mathrm{kHz}$. The Nyquist plot for different variants are shown in Figure 7. The graph demonstrates that the ternary composite $(0.49 \Omega)$ has the least charge transfer resistance compared to PANI $(1.40 \Omega), \mathrm{MnO}_{2}(0.54 \Omega)$ and PAN@CNT $(0.62 \Omega)$ as well as most vertical line parallel to the imaginary axis $\left(-Z^{\prime \prime}\right)$ showing the best charge storage capacity. Similarly, ESR values obtained for $\mathrm{MnO}_{2}$, PANI, PANI@CNT, and PANI@CNT/MnO 2 are $0.45,0.22,0.38$, and $0.48 \Omega$, respectively. The best performing electrode material was then selected for device fabrication. In this case, it is concluded from all above electrochemical studies that ternary 
composite, PANI@CNT/ $\mathrm{MnO}_{2}$ is the best battery type electrode material which can be utilized for hybrid device assembly.

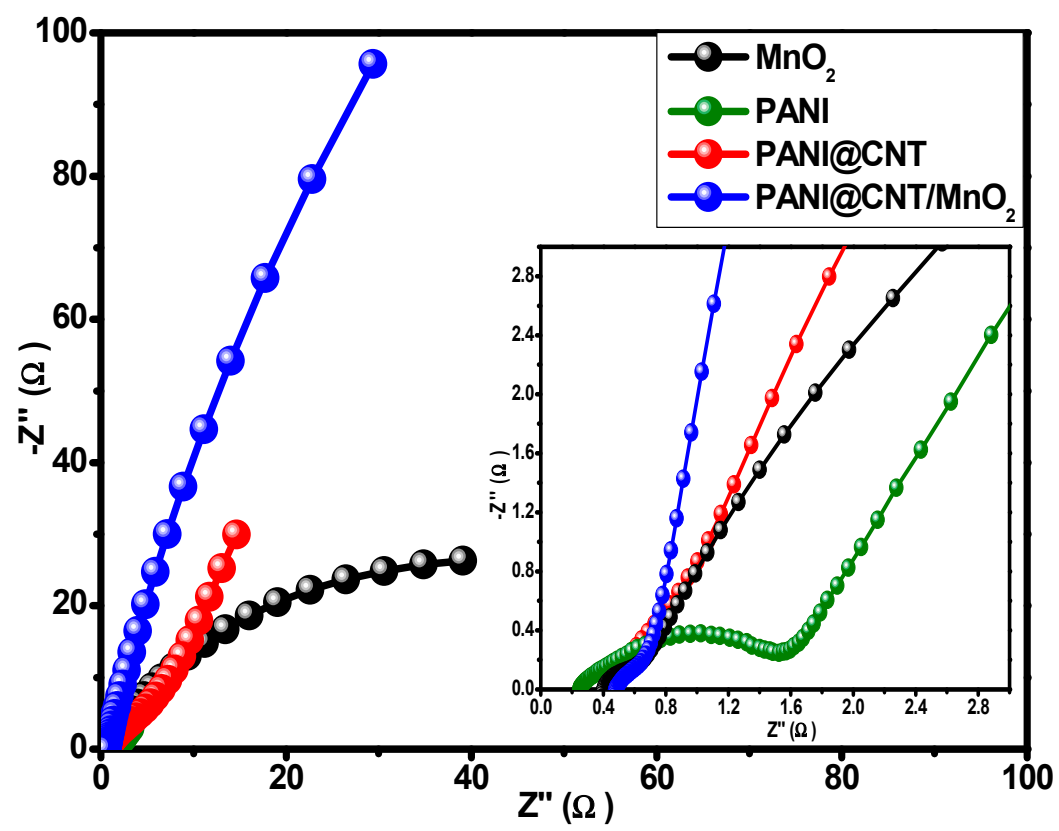

Figure 7. Nyquist plots of the $\mathrm{MnO}_{2}$ nanorods, fibrous PANI, PANI@CNT, and PANI@CNT/MnO 2 ternary composite. Inset Figure 7 shows the electrochemical impedance spectroscopy (EIS) spectrum in high frequency region.

\subsection{Fabrication and Characterization of Two Electrodes Assembly (PANI@CNT/MnO $2 / / A C$ )}

The two electrodes assembly was developed using a nickel foam coated ternary composite, PANI@CNT/ $\mathrm{MnO}_{2}$ as positive electrode (battery-grade material) and activated carbon (AC) coated as negative electrode (capacitive material). Both electrodes were coupled together by placing porous membrane in between them. In this assembly two different electrodes were used, i.e., supercapacitor electrodes and battery type electrodes, known as supercapattery, which can store charge electrostatically and electrochemically. Before combining them together both were tested individually in three electrodes cell to know their working potential window and electrochemical signature. Figure 8a shows that the $\mathrm{AC}$ is capacitive electrode with a potential window of -1 to $0 \mathrm{~V}$ whereas ternary composite is pseudocapacitive with potential window, 0 to $0.5 \mathrm{~V}$. Figure $8 \mathrm{~b}$ shows the graphical demonstration of the assembled device in which positive potential is applied to battery type electrode whereas negative potential to capacitive electrode. The electrochemical studies (CV, GCD and stability) of two electrodes assembly were conducted in $0.1 \mathrm{M} \mathrm{KOH}$ in the potential range of 0 to $1.5 \mathrm{~V}$.

The CV studies were conducted at different potential windows $(0-0.5,0-0.75,0-1.0,0-1.25$ and $0-1.5 \mathrm{~V}$ ) to verify the maximum working potential range as shown in Figure 8c. The assembled hybrid device then scanned at various rates from 3 to $100 \mathrm{mV} \mathrm{s}^{-1}$ at a fix potential window of 0 to $1.5 \mathrm{~V}$ as demonstrated in Figure $8 \mathrm{~d}$ to analyze the rate capability. The shape of the CVs was well conserved even at higher scan rates thereby representing the marvelous rate capability. The shape of the CVs is neither rectangular nor humpy, showing the contribution of both energy storage mechanism, i.e., non-faradaic (capacitive) and faradaic (diffusive). In GCD studies (Figure 9a), similar trend was observed because the curves were not completely rectangular but each one has little shoulder. Here again, the assembled hybrid device demonstrating the charge storage mechanism is contributed by both capacitive and diffusive processes. The $Q_{S}$ values were calculated form the GCD curves for the assembled hybrid device at various current densities using Equation (2). 

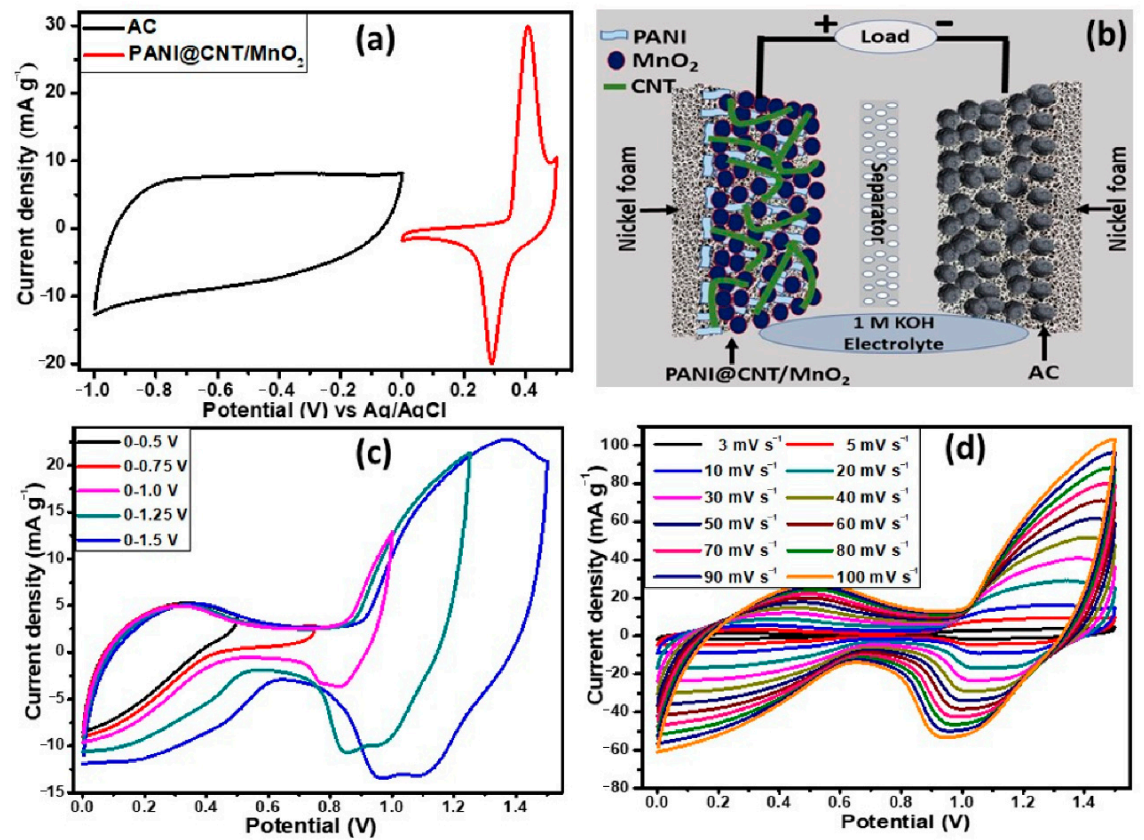

Figure 8. (a) Comparative cyclic voltammetry (CV) curves of PANI@CNT/MnO 2 ternary composite and activated carbon (AC) electrodes performed in a three-electrode cell in $\mathrm{KOH}$ aqueous solution at a scan rate of $10 \mathrm{mV} \mathrm{s}^{-1}$; (b) graphical representation of assembled device; (c) CVs of PANI@CNT/MnO $2 / / A C$ supercapattery measured at different potential windows; and (d) galvanostatic charge-discharge curves of PANI@CNT/ $\mathrm{MnO}_{2} / / \mathrm{AC}$ supercapattery at various current densities.

The highest specific capacity of $131.27 \mathrm{C} \mathrm{g}^{-1}$ was found at current density of $0.4 \mathrm{~A} \mathrm{~g}^{-1}$ for the assembled hybrid device as shown in Figure 9a.

The energy density $(E)$ and power density $(P)$ are the major parameters to assess the working of an energy storage device which were calculated using the following Equations (3) and (4):

$$
\begin{gathered}
E(\mathrm{Wh} / \mathrm{kg})=\frac{\Delta V \times Q_{S}}{2 \times 3.6} \\
P(\mathrm{~W} / \mathrm{kg})=\frac{E \times 3600}{\Delta t}
\end{gathered}
$$

where $Q_{S}, \Delta V$, and $\Delta t$ represent the specific capacity $\left(\mathrm{C} \mathrm{g}^{-1}\right)$, potential window $(V)$ and discharge time (s) of the hybrid device, respectively. The obtained values of energy density and power density are plotted in Figure 9c. The maximum energy density $\left(27.17 \mathrm{Wh} \mathrm{kg}^{-1}\right)$ was obtained at a current density of $0.3 \mathrm{~A} \mathrm{~g} \mathrm{~g}^{-1}$ with the corresponding power density of $298.00 \mathrm{~W} \mathrm{~kg}^{-1}$. An inverse relation was noticed between energy density and power density. When the power density was stepped up from 298.00 to $1995.00 \mathrm{~W} \mathrm{~kg}^{-1}$, energy density depleted down from 20.47 to $15.07 \mathrm{~W} \mathrm{~kg}^{-1}$. These results proved the excellent working of the hybrid assembled device using the novel ternary composite when assessed based on energy density, power density and specific capacity. Another important parameter for energy storage devices is the stability test. The assembled hybrid device was subjected to charge-discharge cycles for over 3500 cycles. Figure $9 \mathrm{~d}$ shows the initial increase in the specific capacity which is due to the activation of polymer composite. A similar trend has been reported in many other articles, especially, where conducting polymers were used in the composites [3,42]. However, after about $\sim 1000$ cycles the stability in the specific capacity was observed, and finally at the end of 3500 cycles, excellent $(119.00 \%)$ specific capacity with coulombic efficiency of $93.50 \%$ was demonstrated by the assembled hybrid device. These results advocate the successful synthesis of porous ternary composite in which three components were combined by a simple hydrothermal method coupled with in-situ oxidative polymerization to achieve synergistic/additional electrochemical effect and subsequently 
utilized as a battery type electrode material in supercapattery. We compared our results with the reported literature on polyaniline based composite electrode materials, which is presented in Table 1.
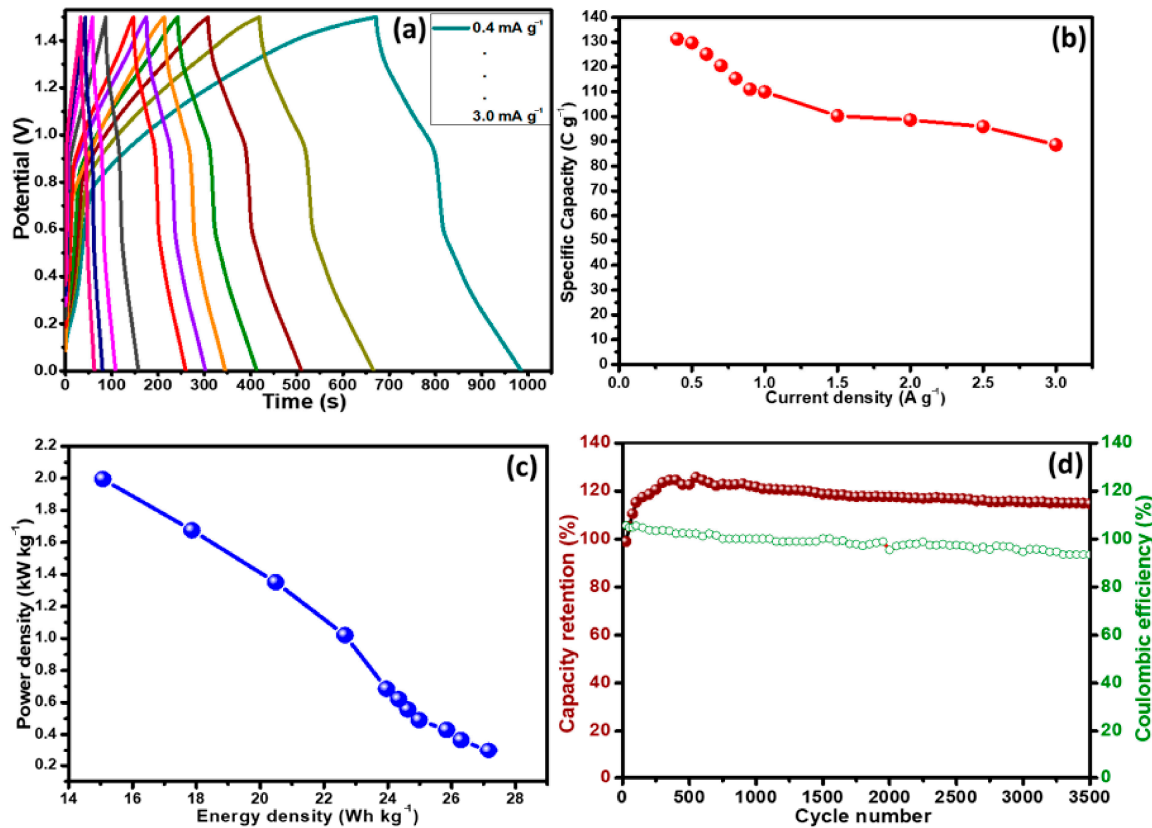

Figure 9. (a) GCD plot of PANI@CNT/MnO $\mathrm{Mn}_{2}$ ternary composite for the assembled hybrid device, (b) current density versus specific capacity, (c) energy density versus power density change, and (d) cyclic performance and coulombic efficiency of the PANI@CNT/ $\mathrm{MnO}_{2}$ ternary composite based hybrid device as a function of the number of cycles at a current density of $3.0 \mathrm{~A} \mathrm{~g}^{-1}$ in $0.1 \mathrm{M} \mathrm{KOH}$.

Table 1. Polyaniline based composite electrode materials for supercapacitors.

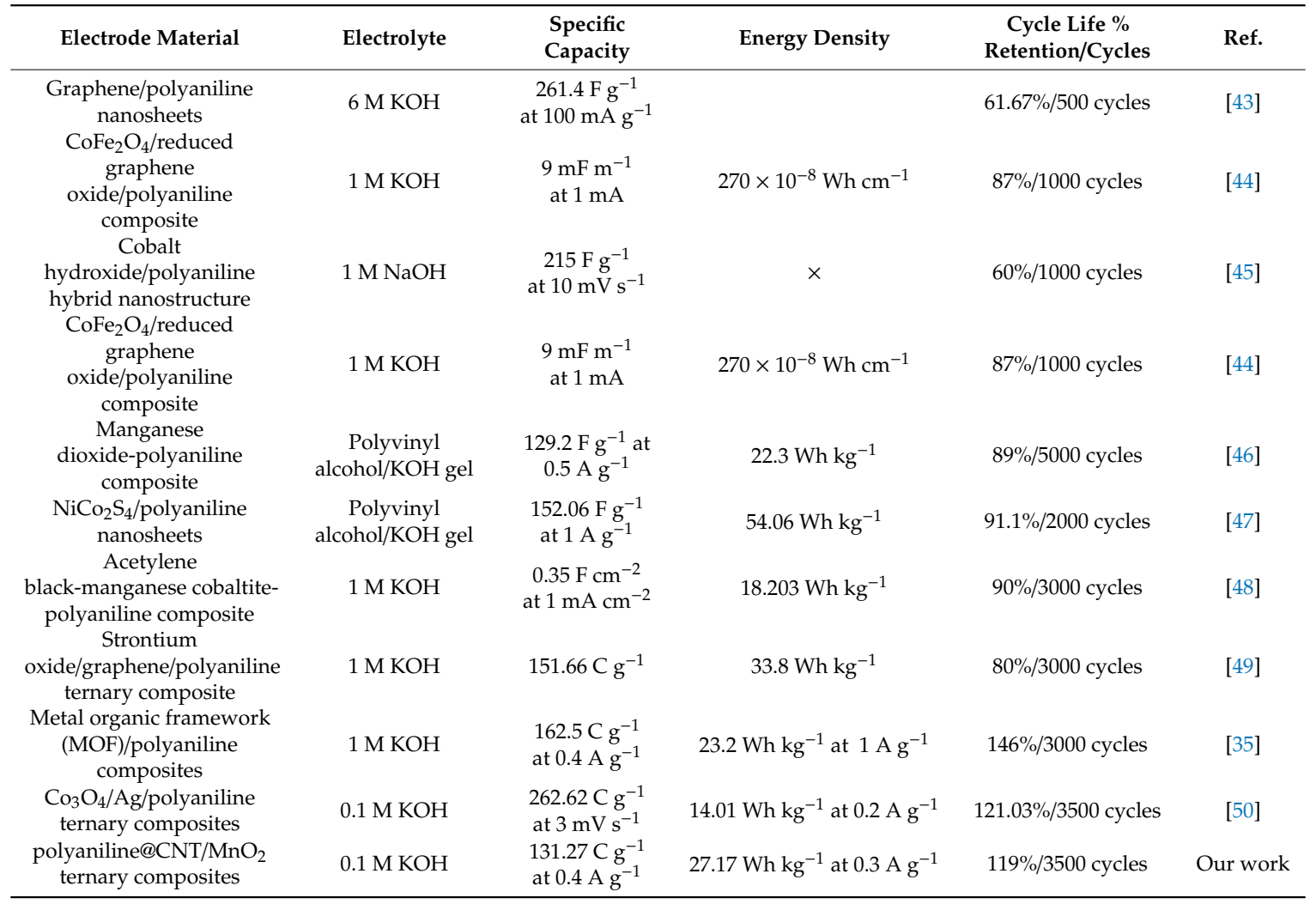




\section{Conclusions}

In summary, PANI@CNT/ $\mathrm{MnO}_{2}$ nanocomposites was prepared by the combination of in-situ oxidative polymerization and hydrothermal reaction. The FESEM images showed fibers with interrupted or rough surfaces, which is expected to provide an enhanced surface area and facilitate in the transport of ions or charge carriers. The XRD and XPS analyses of PANI@CNT/MnO $\mathrm{M}_{2}$ showed peaks corresponding to the $\mathrm{MnO}_{2}, \mathrm{CNT}$, and PANI, thereby suggesting the efficacy of the synthesis methodology. The electrochemical studies were carried out to analyze the voltammetric character through a typical three electrode system and applied voltages ranging from 0 to 0.5 V. PANI@CNT/ $\mathrm{MnO}_{2}$ battery type ternary nanocomposite showed highest current density of $154.84 \mathrm{~mA} \mathrm{~g}^{-1} @ 50 \mathrm{mV} \mathrm{s}^{-1}$ and specific capacity of $143.26 \mathrm{~F} \mathrm{~g}^{-1}$ at $3 \mathrm{mV} \mathrm{s}^{-1}$ in comparison to 34.71 for $\mathrm{MnO}_{2}, 86.02$ for PANI and $118.47 \mathrm{C} \mathrm{g}^{-1}$ for PANI@CNT. The galvanostatic charge-discharge studies showed that there is systematic increase in the discharge time for all four variants but PANI@CNT/ $\mathrm{MnO}_{2}$ ternary composite demonstrated the best electrochemical performance in terms of longer discharge duration. The specific capacity from GCD curves at current density $0.3 \mathrm{~A} \mathrm{~g}^{-1}$ were $32.98,95.04,128.73$, and $153.82 \mathrm{C} \mathrm{g}^{-1}$ for $\mathrm{MnO}_{2}$, PANI, PANI@CNT, and PANI@CNT/MnO ${ }_{2}$, respectively. The Nyquist plots for the performed EIS study showed that PANI@CNT/ $\mathrm{MnO}_{2}$ has the smallest radius among all other electrode materials at high frequencies with a more vertical line at low frequencies parallel to the imaginary axis. This confirms that PANI@CNT/ $\mathrm{MnO}_{2}$ battery type material possesses highest capacity of charge storage and least resistance against the charge transfer. The enhanced performance of PANI@CNT/MnO $\mathrm{Mn}_{2}$ can be attributed to the high thermal and electrical conductivity of the constituents which assist in smooth conductive path for the transportation of charge carriers along $\mathrm{MnO}_{2}, \mathrm{CNT}$ and PANI. Apart from this, the assembled supercapattery-consisting of the battery type ternary composite as a positive and an activated carbon as the negative electrode-delivered the highest specific capacity of $131.27 \mathrm{C} \mathrm{g}^{-1}$ which was found at a current density of $0.4 \mathrm{~A} \mathrm{~g}^{-1}$. The maximum energy density of $27.17 \mathrm{Wh} \mathrm{kg}^{-1}$ was obtained at a current density of $0.3 \mathrm{~A} \mathrm{~g}^{-1}$ with the corresponding power density of $298.00 \mathrm{~W} \mathrm{~kg}^{-1}$. The cyclic stability of the fabricated device showed that the PANI@CNT/ $\mathrm{MnO}_{2}$ battery type ternary composite retained $119 \%$ capacitance even after 3500 cycles. The high specific capacitance combined with excellent cyclic stability projects PANI@CNT/MnO 2 to be a promising battery type material for high performance supercapattery.

Author Contributions: Conceptualization, J.I., M.O.A. and A.N.; methodology, J.I. and M.O.A.; writing-original draft preparation, S.W., A.A.-G. and M.G.A.; writing-review and editing, P.K., R.J., S.B. and A.H.R. All authors have read and agreed to the published version of the manuscript.

Funding: The Deanship of Scientific Research (DSR) at King Abdulaziz University, Jeddah, Saudi Arabia has funded this project under grant No. (FP-181-42).

Acknowledgments: We acknowledge the support from King Abdulaziz University, Jeddah 21589, Saudi Arabia.

Conflicts of Interest: The authors declare no conflict of interest.

\section{References}

1. Whiting, K.; Carmona, L.G.; Sousa, T. A review of the use of exergy to evaluate the sustainability of fossil fuels and non-fuel mineral depletion. Renew. Sustain. Energy Rev. 2017, 76, 202-211. [CrossRef]

2. Bello, I.T.; Oladipo, A.O.; Adedokun, O.; Dhlamini, S.M. Recent advances on the preparation and electrochemical analysis of $\mathrm{MoS}_{2}$-based materials for supercapacitor applications: A mini-review. Mater. Today Commun. 2020, 25, 101664. [CrossRef]

3. Iqbal, M.Z.; Khan, A.; Numan, A.; Alzaid, M.; Iqbal, J. Facile sonochemical synthesis of strontium phosphate based materials for potential application in supercapattery devices. Int. J. Hydrog. Energy 2020, 45, 32331-32342. [CrossRef]

4. Alshahrie, A.; Ansari, M.O. High Performance Supercapacitor Applications and DC Electrical Conductivity Retention on Surfactant Immobilized Macroporous Ternary Polypyrrole/Graphitic- $\mathrm{C}_{3} \mathrm{~N}_{4} @ G r a p h e n e$ Nanocomposite. Electron. Mater. Lett. 2019, 15, 238-246. [CrossRef] 
5. Ansari, S.A.; Ansari, M.O.; Cho, M.H. Facile and scale up synthesis of red phosphorus-graphitic carbon nitride heterostructures for energy and environment applications. Sci. Rep. 2016, 6, 27713. [CrossRef] [PubMed]

6. Iqbal, J.; Numan, A.; Jafer, R.; Bashir, S.; Jilani, A.; Mohammad, S.; Khalid, M.; Ramesh, K.; Ramesh, S. Ternary nanocomposite of cobalt oxide nanograins and silver nanoparticles grown on reduced graphene oxide conducting platform for high-performance supercapattery electrode material. J. Alloys Compd. 2020, 821, 153452. [CrossRef]

7. Xiong, C.; Li, M.; Nie, S.; Dang, W.; Zhao, W.; Dai, L.; Ni, Y. Non-carbonized porous lignin-free wood as an effective scaffold to fabricate lignin-free Wood@ Polyaniline supercapacitor material for renewable energy storage application. J. Power Sources 2020, 471, 228448. [CrossRef]

8. Parveen, N.; Ansari, M.O.; Cho, M.H. Route to high surface area, mesoporosity of polyaniline-titanium dioxide nanocomposites via one pot synthesis for energy storage applications. Ind. Eng. Chem. Res. 2016, 55, 116-124. [CrossRef]

9. Iqbal, J.; Numan, A.; Ansari, M.O.; Jagadish, P.R.; Jafer, R.; Bashir, S.; Mohamad, S.; Ramesh, K.; Ramesh, S. Facile synthesis of ternary nanocomposite of polypyrrole incorporated with cobalt oxide and silver nanoparticles for high performance supercapattery. Electrochim. Acta 2020, 348, 136313. [CrossRef]

10. Dhawale, D.; Salunkhe, R.; Jamadade, V.; Dubal, D.; Pawar, S.; Lokhande, C. Hydrophilic polyaniline nanofibrous architecture using electrosynthesis method for supercapacitor application. Curr. Appl. Phys. 2010, 10, 904-909. [CrossRef]

11. Liang, M.; Xin, H. Microwave to Terahertz: Characterization of Carbon-Based Nanomaterials. IEEE Microw. Mag. 2014, 15, 40-51. [CrossRef]

12. Bianco, A.; Chen, Y.; Frackowiak, E.; Holzinger, M.; Koratkar, N.; Meunier, V.; Mikhailovsky, S.; Strano, M.; Tascon, J.M.D.; Terrones, M. Carbon science perspective in 2020: Current research and future challenges. Carbon 2020, 161, 373-391. [CrossRef]

13. Parveen, N.; Mahato, N.; Ansari, M.O.; Cho, M.H. Enhanced electrochemical behavior and hydrophobicity of crystalline polyaniline@ graphene nanocomposite synthesized at elevated temperature. Compos. Part B Eng. 2016, 87, 281-290. [CrossRef]

14. Deng, M.; Yang, B.; Hu, Y. Polyaniline deposition to enhance the specific capacitance of carbon nanotubes for supercapacitors. J. Mater. Sci. 2005, 40, 5021-5023. [CrossRef]

15. Sharma, A.K.; Sharma, Y. Pseudo Capacitive Studies of Polyaniline-Carbon Nanotube Composites as Electrode Material for Supercapacitor. Anal. Lett. 2012, 45, 2075-2085. [CrossRef]

16. Wu, D.; Xie, X.; Zhang, Y.; Zhang, D.; Du, W.; Zhang, X.; Wang, B. $\mathrm{MnO}_{2} /$ Carbon Composites for Supercapacitor: Synthesis and Electrochemical Performance. Front. Mater. 2020, 7. [CrossRef]

17. Xie, Y.; Yang, C.; Chen, P.; Yuan, D.; Guo, K. $\mathrm{MnO}_{2}$-decorated hierarchical porous carbon composites for high-performance asymmetric supercapacitors. J. Power Sources 2019, 425, 1-9. [CrossRef]

18. Wang, J.-G.; Kang, F.; Wei, B. Engineering of $\mathrm{MnO}_{2}$-based nanocomposites for high-performance supercapacitors. Prog. Mater. Sci. 2015, 74, 51-124. [CrossRef]

19. Li, L.; Hu, Z.A.; An, N.; Yang, Y.Y.; Li, Z.M.; Wu, H.Y. Facile Synthesis of $\mathrm{MnO}_{2} / \mathrm{CNT}_{\text {s }}$ Composite for Supercapacitor Electrodes with Long Cycle Stability. J. Phys. Chem. C 2014, 118, 22865-22872. [CrossRef]

20. Liu, T.; Shao, G.; Ji, M.; Wang, G. Polyaniline/ $\mathrm{MnO}_{2}$ composite with high performance as supercapacitor electrode via pulse electrodeposition. Polym. Compos. 2015, 36, 113-120. [CrossRef]

21. Wang, J.-G.; Yang, Y.; Huang, Z.-H.; Kang, F. Shape-controlled synthesis of hierarchical hollow urchin-shape $\alpha-\mathrm{MnO}_{2}$ nanostructures and their electrochemical properties. Mater. Chem. Phys. 2013, 140, 643-650. [CrossRef]

22. Hassanpoor, S.; Rouhi, N. Electrochemical sensor for determination of trace amounts of cadmium (II) in environmental water samples based on $\mathrm{MnO}_{2} / \mathrm{RGO}$ nanocomposite. Int. J. Environ. Anal. Chem. 2019, 1-20. [CrossRef]

23. Ansari, M.O.; Khan, M.M.; Ansari, S.A.; Lee, J.; Cho, M.H. Enhanced thermoelectric behaviour and visible light activity of $\mathrm{Ag} @ \mathrm{TiO}_{2} /$ polyaniline nanocomposite synthesized by biogenic-chemical route. RSC Adv. 2014, 4, 23713-23719. [CrossRef]

24. Kumar, R.; Ansari, M.O.; Alshahrie, A.; Darwesh, R.; Parveen, N.; Yadav, S.K.; Barakat, M.A.; Cho, M.H. Adsorption modeling and mechanistic insight of hazardous chromium on para toluene sulfonic acid immobilized-polyaniline@CNTs nanocomposites. J. Saudi Chem. Soc. 2019, 23, 188-197. [CrossRef] 
25. Su, D.; Ahn, H.-J.; Wang, G. Hydrothermal synthesis of $\alpha-\mathrm{MnO}_{2}$ and $\beta-\mathrm{MnO}_{2}$ nanorods as high capacity cathode materials for sodium ion batteries. J. Mater. Chem. A 2013, 1, 4845-4850. [CrossRef]

26. Bhadra, S.; Khastgir, D. Determination of crystal structure of polyaniline and substituted polyanilines through powder X-ray diffraction analysis. Polym. Test. 2008, 27, 851-857. [CrossRef]

27. Ansari, M.O.; Yadav, S.K.; Cho, J.W.; Mohammad, F. Thermal stability in terms of DC electrical conductivity retention and the efficacy of mixing technique in the preparation of nanocomposites of graphene/polyaniline over the carbon nanotubes/polyaniline. Compos. Part B Eng. 2013, 47, 155-161. [CrossRef]

28. Ansari, M.O.; Ansari, S.P.; Yadav, S.K.; Anwer, T.; Cho, M.H.; Mohammad, F. Ammonia vapor sensing and electrical properties of fibrous multi-walled carbon nanotube/polyaniline nanocomposites prepared in presence of cetyl-trimethylammonium bromide. J. Ind. Eng. Chem. 2014, 20, 2010-2017. [CrossRef]

29. Zhang, X.; Zhang, J.; Quan, J.; Wang, N.; Zhu, Y. Surface-enhanced Raman scattering activities of carbon nanotubes decorated with silver nanoparticles. Analyst 2016, 141, 5527-5534. [CrossRef]

30. Yuan, C.-L.; Chang, C.-P.; Hong, Y.-S.; Sung, Y. Fabrication of MWNTs-PANI composite-A chemiresistive sensor material for the detection of explosive gases. Mater. Sci. Pol. 2009, 27, 509-520.

31. Wang, N.; Chen, Y.; Ren, J.; Huang, X.; Chen, X.; Li, G.; Liu, D. Electrically conductive polyaniline/polyimide microfiber membrane prepared via a combination of solution blowing and subsequent in situ polymerization growth. J. Polym. Res. 2017, 24, 42. [CrossRef]

32. Peng, H.; Ma, G.; Sun, K.; Mu, J.; Zhou, X.; Lei, Z. A novel fabrication of nitrogen-containing carbon nanospheres with high rate capability as electrode materials for supercapacitors. RSC Adv. 2015, 5, 12034-12042. [CrossRef]

33. Subramanian, V.; Zhu, H.; Vajtai, R.; Ajayan, P.M.; Wei, B. Hydrothermal Synthesis and Pseudocapacitance Properties of $\mathrm{MnO}_{2}$ Nanostructures. J. Phys. Chem. B 2005, 109, 20207-20214. [CrossRef] [PubMed]

34. Xie, G.; Liu, X.; Li, Q.; Lin, H.; Li, Y.; Nie, M.; Qin, L. The evolution of $\alpha$-MnO 2 from hollow cubes to hollow spheres and their electrochemical performance for supercapacitors. J. Mater. Sci. 2017, 52, 10915-10926. [CrossRef]

35. Iqbal, M.Z.; Faisal, M.M.; Alzaid, S.R.A.M. A facile approach to investigate the charge storage mechanism of MOF/PANI based supercapattery devices. Solid State Ion. 2020, 354, 115411. [CrossRef]

36. Jiang, W.; Hu, F.; Yan, Q.; Wu, X. Investigation on electrochemical behaviors of $\mathrm{NiCo}_{2} \mathrm{O}_{4}$ battery-type supercapacitor electrodes: The role of an aqueous electrolyte. Inorg. Chem. Front. 2017, 4, 1642-1648. [CrossRef]

37. Iqbal, J.; Li, L.; Numan, A.; Rafique, S.; Jafer, R.; Mohamad, S.; Khalid, M.; Ramesh, K.; Ramesh, S. Density functional theory simulation of cobalt oxide aggregation and facile synthesis of a cobalt oxide, gold and multiwalled carbon nanotube based ternary composite for a high performance supercapattery. New J. Chem. 2019, 43, 13183-13195. [CrossRef]

38. Park, H.-W.; Kim, T.; Huh, J.; Kang, M.; Lee, J.E.; Yoon, H. Anisotropic growth control of polyaniline nanostructures and their morphology-dependent electrochemical characteristics. ACS Nano 2012, 6, 7624-7633. [CrossRef]

39. Kumar, M.S.; Yasoda, K.Y.; Batabyal, S.K.; Kothurkar, N.K. Carbon-polyaniline nanocomposites as supercapacitor materials. Mater. Res. Express 2018, 5, 045505. [CrossRef]

40. Omar, F.S.; Numan, A.; Bashir, S.; Duraisamy, N.; Vikneswaran, R.; Loo, Y.-L.; Ramesh, K.; Ramesh, S. Enhancing rate capability of amorphous nickel phosphate supercapattery electrode via composition with crystalline silver phosphate. Electrochim. Acta 2018, 273, 216-228. [CrossRef]

41. Numan, A.; Khalid, M.; Ramesh, S.; Ramesh, K.; Shamsudin, E.; Zhan, Y.; Jagadesh, P. Facile sonochemical synthesis of 2D porous $\mathrm{Co}_{3} \mathrm{O}_{4}$ nanoflake for supercapattery. J. Alloys Compd. 2020, 819, 153019. [CrossRef]

42. Shahabuddin, S.; Numan, A.; Shahid, M.M.; Khanam, R.; Saidur, R.; Pandey, A.; Ramesh, S. Polyaniline-SrTiO 3 nanocube based binary nanocomposite as highly stable electrode material for high performance supercapaterry. Ceram. Int. 2019, 45, 11428-11437. [CrossRef]

43. Li, X.; Song, H.; Zhang, Y.; Wang, H.; Du, K.; Li, H.; Yuan, Y.; Huang, J. Enhanced electrochemical capacitance of graphene nanosheets coating with polyaniline for supercapacitors. Int. J. Electrochem Sci. 2012, 7, 5163-5171.

44. Sankar, K.V.; Selvan, R.K. Fabrication of flexible fiber supercapacitor using covalently grafted $\mathrm{CoFe}_{2} \mathrm{O}_{4} /$ reduced graphene oxide/polyaniline and its electrochemical performances. Electrochim. Acta 2016, 213, 469-481. [CrossRef] 
45. Shendkar, J.H.; Zate, M.; Tehare, K.; Jadhav, V.V.; Mane, R.S.; Naushad, M.; Yun, J.M.; Kim, K.H. Polyaniline-cobalt hydroxide hybrid nanostructures and their supercapacitor studies. Mater. Chem. Phys. 2016, 180, 226-236. [CrossRef]

46. Ghosh, K.; Yue, C.Y.; Sk, M.M.; Jena, R.K. Development of 3D urchin-shaped coaxial manganese dioxide@ polyaniline $\left(\mathrm{MnO}_{2} @\right.$ PANI) composite and self-assembled 3D pillared graphene foam for asymmetric all-solid-state flexible supercapacitor application. ACS Appl. Mater. Interfaces 2017, 9, 15350-15363. [CrossRef]

47. He, X.; Liu, Q.; Liu, J.; Li, R.; Zhang, H.; Chen, R.; Wang, J. High-performance all-solid-state asymmetrical supercapacitors based on petal-like $\mathrm{NiCO}_{2} \mathrm{O}_{4}$ /Polyaniline nanosheets. Chem. Eng. J. 2017, 325, 134-143. [CrossRef]

48. Das, T.; Verma, B. Polyaniline based ternary composite with enhanced electrochemical properties and its use as supercapacitor electrodes. J. Energy Storage 2019, 26, 100975. [CrossRef]

49. Iqbal, M.; Faisal, M.M.; Sulman, M.; Ali, S.R.; Alzaid, M. Facile synthesis of strontium oxide/polyaniline/graphene composite for the high-performance supercapattery devices. J. Electroanal. Chem. 2020, 879, 114812. [CrossRef]

50. Iqbal, J.; Numan, A.; Omaish Ansari, M.; Jafer, R.; Jagadish, P.R.; Bashir, S.; Hasan, P.M.Z.; Bilgrami, A.L.; Mohamad, S.; Ramesh, K.; et al. Cobalt Oxide Nanograins and Silver Nanoparticles Decorated Fibrous Polyaniline Nanocomposite as Battery-Type Electrode for High Performance Supercapattery. Polymers 2020, 12, 2816. [CrossRef]

Publisher's Note: MDPI stays neutral with regard to jurisdictional claims in published maps and institutional affiliations. 